\title{
UPRAVLJANJE RIZICIMA I INTERNA REVIZIJA
}

\section{RISK MANAGEMENT AND INTERNAL AUDIT}

\author{
Zorica Jović \\ Fakultet organizacionih nauka, Beograd, Srbija
}

CMESTE

JEL kategorija rada: G32, M42

\begin{abstract}
Abstrakt
Ljudi preduzimaju aktivnosti upravljanja rizikom radi identifikacije, procene, upravljanja i kontrole svih vrsta događaja ili situacija. Ovo može da se kreće od jednog projekta ili usko definisanih tipova rizika, na primer tržišni rizik, do pretnji i šansi sa kojima se suočava organizacija kao celina. Organizacije su pod pritiskom da identifikuju sve poslovne rizike sa kojima se suočavaju - socijalne, etičke i rizike životne sredine kao i finansijske i operativne i da objasne da se njima upravlja na prihvatljivom nivou. Upravljanje rizikom je osnovni element korporativnog upravljanja. Rukovodstvo je odgovorno za utvrđivanje $i$ funkcionisanje okvira za upravljanje rizikom u ime odbora. Upravljanje rizikom preduzeća donosi mnoge koristi koje su rezultat njegovog strukturiranog, konzistentnog i koordiniranog pristupa. Ključna uloga internih revizora u vezi sa upravljanjem rizicima preduzeća treba da bude u obezbeđivanju uveravanja o efektivnosti upravljanja rizicima rukovodstva. Kada interna revizija proširi svoje aktivnosti izvan ove ključne uloge, ona treba da primeni određene mere obezbeđenja, uključujući i to da angažmane tretira kao usluge konsaltinga i da primenjuje sve relevantne standarde. Na ovaj način će interna revizija zaštititi svoju nezavisnost i objektivnost svojih usluga uveravanja.
\end{abstract}

Ključne reči: rizik, upravljanje rizicima, interna revizija, registar rizika, procena rizika, tretiranje rizika.

\begin{abstract}
People undertake risk management activities to identify, assess, manage, and control all types of events or situations. This can range from a single project or narrowly defined types of risk, for example, market risk, to the threats and opportunities faced by the organization. Organizations are under pressure to identify all business risks they face - social, ethical, and environmental risks as well as financial and operational - and to explain that they are being managed at an acceptable level. Risk management is a basic element of corporate governance. Management is responsible for establishing and operating the risk management framework on behalf of the board. A company's risk management brings many benefits that result from its structured, consistent, and coordinated approach. The key role of internal auditors concerning enterprise risk management should be to assure the effectiveness of risk management to

Adresa autora:

Zorica Jović

部'zorica.jovic2007@gmail.com

management. When an internal audit extends its activities beyond this key role, it should apply certain security measures, including treating engagements as consulting
\end{abstract}


services and applying all relevant standards. In this way, an internal audit will protect its independence and the objectivity of its assurance services.

Keywords: risk, risk management, internal audit, risk register, risk assessment, risk treatment.

\section{UVOD}

Naglasak na upravljanje rizikom sada primenjuju mnoge velike organizacije kao moćno poslovno oruđe koje, ako se koristi na pravi način, poboljšava učinak. Kodeksi dobrog korporativnog upravljanja zahtevaju od odbora da uvedu sistem upravljanja rizikom i da informiše svoje akcionare o ovom sistemu.

Upravljanje rizikom je poseban deo nadležnosti internog revizora kojim treba da se pomogne unapređenje efektivnog upravljanja rizikom $u$ organizaciji i da pruže uveravanje odboru o ovom pitanju. Velike organizacije razumeju rizike po svoje poslovanje i mogu da zadovolje regulatorna tela svojim metodama upravljanja rizikom. Takođe razumeju profil rizika i način na koji se rizik širi i kako se rizikom bavi u preduzeću na različite načine, koji pak doprinose formiranju šireg plana koji ima smisla za sve različite poslovne jedinice, proizvodne linije, radne jedinice, projektne timove i prateće funkcije. Odluke na svim nivoima treba da se donose $u$ okviru integrisanog procesa upravljanja rizikom kojim se obezbeđuje da se svi postojeći i novi rizika analiziraju i ublažavaju prema potrebi. (Pickett, Interni revizor u praksi, 2004, str. 39)

\section{2 ŠTA JE RIZIK?}

Rizik predstavlja niz izazova koje treba savladati. Ključno obeležje ovog izazova je što se on javlja kada treba da se donese važna odluka. Rizik nema stvarni oblik, osim ako ga mi ne usmerimo u sopstvenom pravcu, odnosno u pravcu cilja koji želimo da ostvarimo. Rizici koji se odnose na postizanje ciljeva utiču na organizacije tako što nas odvraćaju od usredsređivanja na uspeh i sprečavaju nas da dođemo do nameravanog rezultata.

Čin postavljanja ciljeva sam po sebi se zasniva na postojećim rizicima i rizicima koji se mogu identifikovati, što predstavlja i određenu neizvesnost $u$ vezi sa budućnošću. Rizik $u$ kontekstu postizanja ciljeva ima pretnje i prilike. Mogu se odnositi na sile koje imaju negativan uticaj na ciljeve, tako što predstavljaju pretnju. Dok sa druge strane postoje rizici koji predstavljaju prilike koje se mogu ostvariti, ali koje se mogu propustiti ili ignorisati. Rizik ne treba da se posmatra samo iz negativne perspektive. Procesom pregleda se mogu utvrditi oblasti koje pružaju prilike, one u kojima se efektivno upravljanje rizikom može pretvoriti u konkurentnu prednost (Pickett, 2005, str. 55).

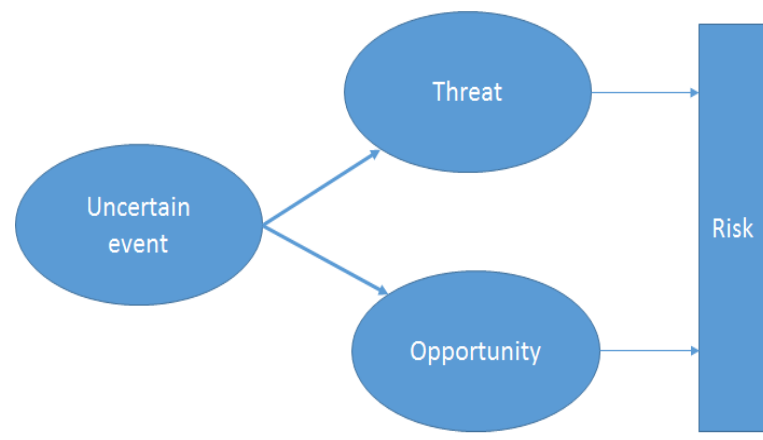

Slika 1 Grafički prikaz risk procesa Izvor: (PRINCE2 Revision, n.d.)

\subsection{Kategorije rizika}

Svaka organizacija će imati sopstveno tumačenje rizika koje će odgovarati tržištu, kulturi i misiji organizacije o kojoj je reč. Da bi povezale proces upravljanja rizikom sa organizacionim sistemima i procedurama, mnoge organizacije kontrolišu rizik na struktuiran način, po odgovarajućim kategorijama. Tri glavne kategorije rizika:

1. Spoljni - nastaju u spoljašnjem okruženju, nisu u potpunosti pod kontrolom organizacije, ali se mogu preduzeti mere za ublažavanje ovih rizika. Čine ih politički, ekonomski, sociokulturni, tehnološki, zakonski/regulatorni rizici kao i rizici u vezi sa životnom sredinom.

2. Operativni - odnose se na operativno poslovanje - tekuće aktivnosti i na održanje i proširenje kapaciteta i sposobnosti. Dalje se dele na kategorije rizika izvršenja, uslužne/proizvodne greške, izvršenja projekta, resursa, odnosa, operativnih aktivnosti, reputacije, upravljanja, detaljnog ispitivanja, otpornosti i sigurnosti.

3. Rizici od promene - rizici nastali usled odluke da se nastavi sa aktivnostima koje prevazilaze trenutne mogućnosti. Sastoje se iz ciljeva, promena programa, novih projekata i novih politika (Pickett, 2005, str.73-74). 


\subsection{Tehnike tretiranja rizika}

Ublažavanje rizika može se definisati kao preduzimanje koraka za smanjenje štetnih efekata. Postoje četiri vrste strategija ublažavanja rizika koje su jedinstvene za kontinuitet poslovanja i oporavak od katastrofe.

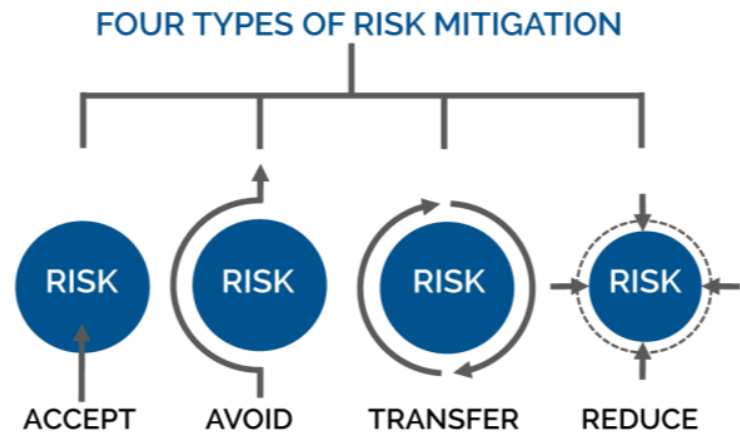

Slika 2 - Tehnike za tretiranje rizika Izvor: (Herrera, 2013)

1. Prihvatanje (Accept) - Prihvatanje rizika ne smanjuje nikakve efekte, ali se i dalje smatra strategijom. Ova strategija je uobičajena opcija kada troškovi drugih opcija upravljanja rizikom, kao što su izbegavanje ili ograničenje, mogu premašiti troškove samog rizika. Kompanija koja ne želi da troši mnogo novca na izbegavanje rizika koji nemaju veliku mogućnost nastanka koristiće strategiju prihvatanja rizika.

2. Izbegavanje (Avoid) - Izbegavanje rizika je suprotno od prihvatanja rizika. To je akcija kojom se izbegava bilo kakvo izlaganje riziku. Važno je napomenuti da je izbegavanje rizika obično najskuplja od svih opcija ublažavanja rizika.

3. Prenošenje (Transfer) - Prenošenje rizika je uključivanje prenošenja rizika na voljnu treću stranu. $\mathrm{Na}$ primer, brojne kompanije preusmeravaju određene operacije kao što su služba za korisnike, usluge obračuna zarada itd. To može biti korisno za kompaniju ako preneti rizik nije osnovna nadležnost te kompanije. Takođe se može koristiti kako bi se kompanija mogla više usredsrediti na svoje ključne kompetencije.

4. Smanjenje (Reduce) - Ograničavanje rizika je najčešća strategija upravljanja rizikom koju koriste preduzeća. Ova strategija ograničava izloženost kompanije preduzimanjem neke mere. To je strategija koja koristi malo prihvatanja rizika uz malo izbegavanja rizika ili prosek oba. Primer ograničenja rizika mogao bi biti kompanija koja prihvata da disk jedinica može otkazati i izbegavanjem dugog perioda kvara korišćenjem rezervnih kopija (Herrera, 2013).

\section{CIKLUS UPRAVLJANJA RIZIKOM}

1. Ciljevi - Ciklus upravljanja rizikom započinje i završava se pružanjem pomoći organizaciji da ostvari svoje ciljeve; korporativne ciljeve na višem nivou i operativne ciljeve na nižem nivou, koji se izvode iz ukupnog strateškog plana. Rizik je svaka neizvesnost koja utiče na poslovne ciljeve u smislu stvarne ili uočene pretnje i propuštene prilike.

2. Politika sprečavanja rizika - Jedan aspekt upravljanja rizikom koji se jasno izdvaja kada se razvijaju odgovarajuća uređenja, odnose se na zajedničke odlike i doslednost - odnosno na doslednu terminologiju, jasnoću uloga u organizaciji, prihvaćenu metodologiju procena i spremnost da se razvija kultura kojom se podržavaju upravljanje rizikom i odgovornost.

3. Identifikacija rizika - ciklus rizika zahteva da postoji formalan proces za identifikovanje rizika preduzeća. Ono se može unaprediti preko istraživanja, poslovne analize, seminara za identifikovanje rizika, revizije i pregleda, ustanovljavanja repera u delatnosti ili redovnih anketa zaposlenih. Jedan od načina olakšavanja faze identifikacije je da se politikom rizika utvrdi niz kategorija rizika. Važno je ne baviti se preterano svrstavanjem rizika u kategorije već se fokusirati na potrebe obuhvatanja svih relevantnih rizika.

4. Procena rizika - kada se dokumentuju rizici, treba da postoji mehanizam kojim se oni stavljaju u kontekst, kojim se izdvaja ono što je važno i krucijalno i izdvajaju se oni rizici koji se za sada mogu ostaviti sa strane. Ideja je da organizacija može da rasporedi svoje osnove resurse oblastima sa velikim rizicima u cilju ublažavanja. Procena rizika se svodi na pripisivanje vrednosti identifikovanim rizicima i utvrđivanje prioriteta među njima. Ovo se obično radi procenjivanjem potencijalnog uticaja rizika, ako on treba da se materijalizuje, a zatim procenjivanjem verovatnoće da će se rizik zaista i materijalizovati.

5. Ublažavanje rizika - Visoki nivoi neprihvatljivih rizika se moraju rešavati. Odnosno, treba da se ublažavaju kako bi se sveli na nivo koji se uklapa u mogućnost prihvatanja rizika te organizacije. 
Ublažavanje se odnosi na uspostavljanje kontrola gde su one neophodne. Kontrole povećavaju izvesnost da će se rizici rešavati i samim tim postoji veća šansa da se ciljevi ostvare.

6. Upravljanje rizikom - ova faza održava celokupnu reakciju na rizik u organizaciji, odnosno usvajanje strategije upravljanja rizikom. Reakcija na rizik zavisi od prirode rizika i o tome da li se radi o riziku velikog, srednjeg ili malog prioriteta. Neki rizici se moraju prihvatiti, jer se malo toga može uraditi da bi se oni ublažili ili je trošak takvog ublažavanja suviše visok. Ovde se strategija upravljanja rizikom može svoditi na ograničavanje štete i planove za nepredviđene situacije. Verovatnoća pojave drugih rizika može biti toliko mala da se mogu zanemariti (ili se može obezbediti osiguravanje protiv njih). Ukupna strategija kojom se obuhvataju svi nivoi i delovi organizacije se naziva upravljanje rizikom celog preduzeća. Ovde se sve pretnje preduzeću, uključujući rizik proizvoda, poslovanja, pomoćnih usluga i projektni rizik, spadaju pod okrilje pristupa upravljanja rizikom.

7. Pregled - Rezultat aktivnosti procene rizika može biti izrada mapa i registra rizika, kojima se uređuju dokumentovani rizici za relevantne procese, proizvode, programe, projekte ili jedinice koje se koriste za definisanje posla. Proces pregleda se više odnosi na razvoj prave kulture nego samo na zahtev za jednostavnim ažuriranjem procene prošlih rizika.

8. Izveštaji - mnogi sistemi za izveštavanje o riziku se svode na registre rizika koji se formiraju tokom timskih radionica organizovanih u cilju pregleda rizika i kontrola u raznim operativnim oblastima u celoj organizaciji. Registri obuhvataju važnu dokumentaciju, tabele koje sadrže sledeće informacije: cilj poslovnog procesa, opis rizika, uticaj, verovatnoća, rangiranje, potrebne radnje (odgovor na rizik), nosilac rizika, rok za izvršenje, datum sledeće provere.

\subsection{Procena rizika}

Veličina učinka ostvarenja razmatranog scenarija na izvršavanje poslovnih procesa, pravne obaveze, regulatorne obaveze ili reputaciju, ocenjuje se kvalitativno na numeričkoj skali od 1 do 3:

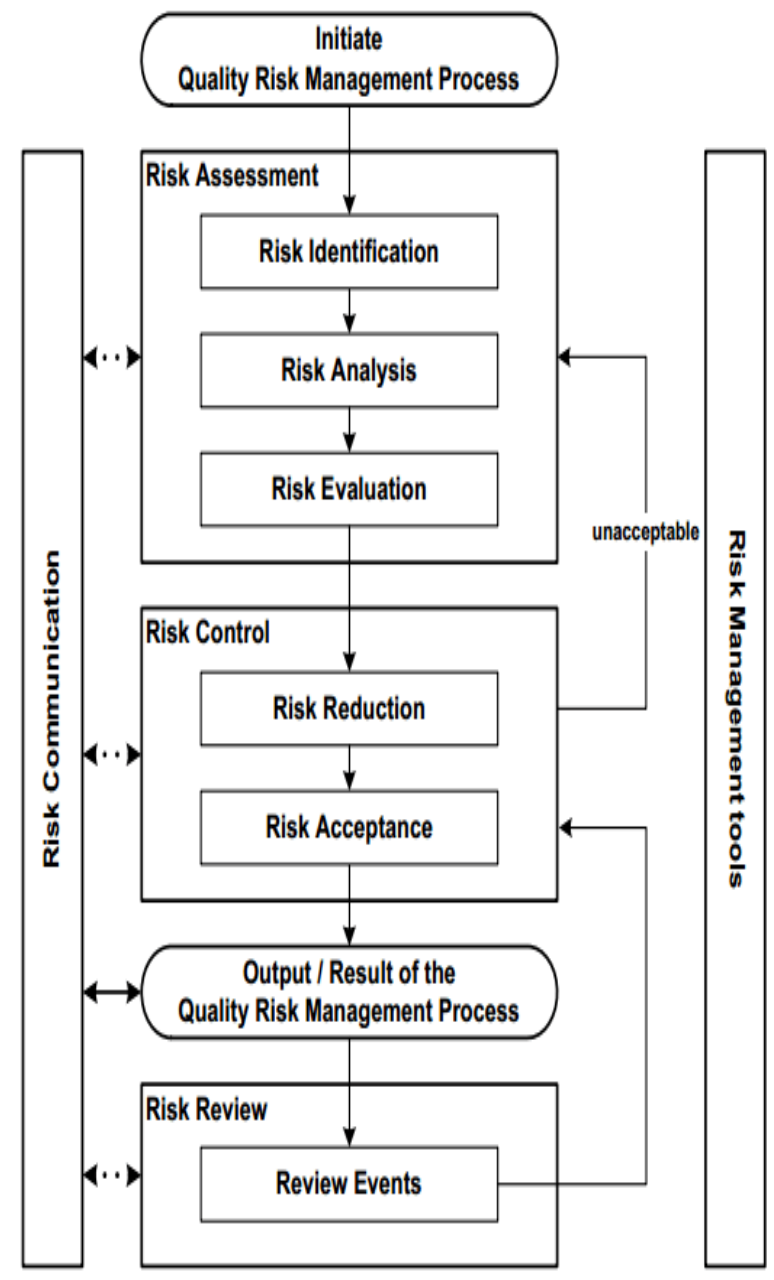

Slika 3 - Prikaz procesa upravljanja rizicima Izvor: (Quality Risk Management Terminologies, pharmamirror.com)

1. mali učinak: Ugrožavanje poverljivosti, celovitosti ili raspoloživosti informacija u razmatranom scenariju predstavlja mali nepovoljan učinak na izvršavanje poslovnih procesa, pravne obaveze, regulatorne obaveze ili reputaciju;

2. srednji učinak: Ugrožavanje poverljivosti, celovitosti ili raspoloživosti informacija u razmatranom scenariju predstavlja srednji nepovoljan učinak na izvršavanje poslovnih procesa, pravne obaveze, regulatorne obaveze ili reputaciju;

3. veliki učinak: Ugrožavanje poverljivosti, celovitosti ili raspoloživosti informacija u razmatranom scenariju predstavlja veliki nepovoljan učinak na izvršavanje poslovnih procesa, pravne obaveze, regulatorne obaveze ili reputaciju.

Nivo rizika informacijske sigurnosti, odnosno rizika gubitka poverljivosti, raspoloživosti ili 
integriteta informacija, određuje se kao zbir verovatnosti ostvarenja razmatranog scenarija $\mathrm{i}$ veličine učinka njegovog ostvarenja:

Koraci procene rizika:

I. faza - predkoraci: Osnovno i detaljno snimanje organizacijskih i tehničkih sigurnosnih mera.
II. faza - procena: Procena rizika i izračun rizika.

III. faza - obrada rizika: Odabir načina tretiranja rizika i implementacija/poboljšanje sigurnosnih mera.

Nivo rizika = Verovatnoća ostvarenja scenarija + učinak ostvarenja scenarija

Tabela 1. Matrica nivoa rizika

\begin{tabular}{|l|c|c|c|}
\hline Verovatnoća ostvarenja scenarija & \multicolumn{3}{|c|}{ Nivo rizika } \\
\hline Velika (3) & 4 & 5 & 6 \\
\hline Srednja (2) & 3 & 4 & 5 \\
\hline Mala (1) & 2 & 3 & 4 \\
\hline Učinak ostvarenja rizika & Mali (1) & Srednji (2) & Veliki (3) \\
\hline
\end{tabular}

Tabela 2. Primer izveštaja o proceni rizika

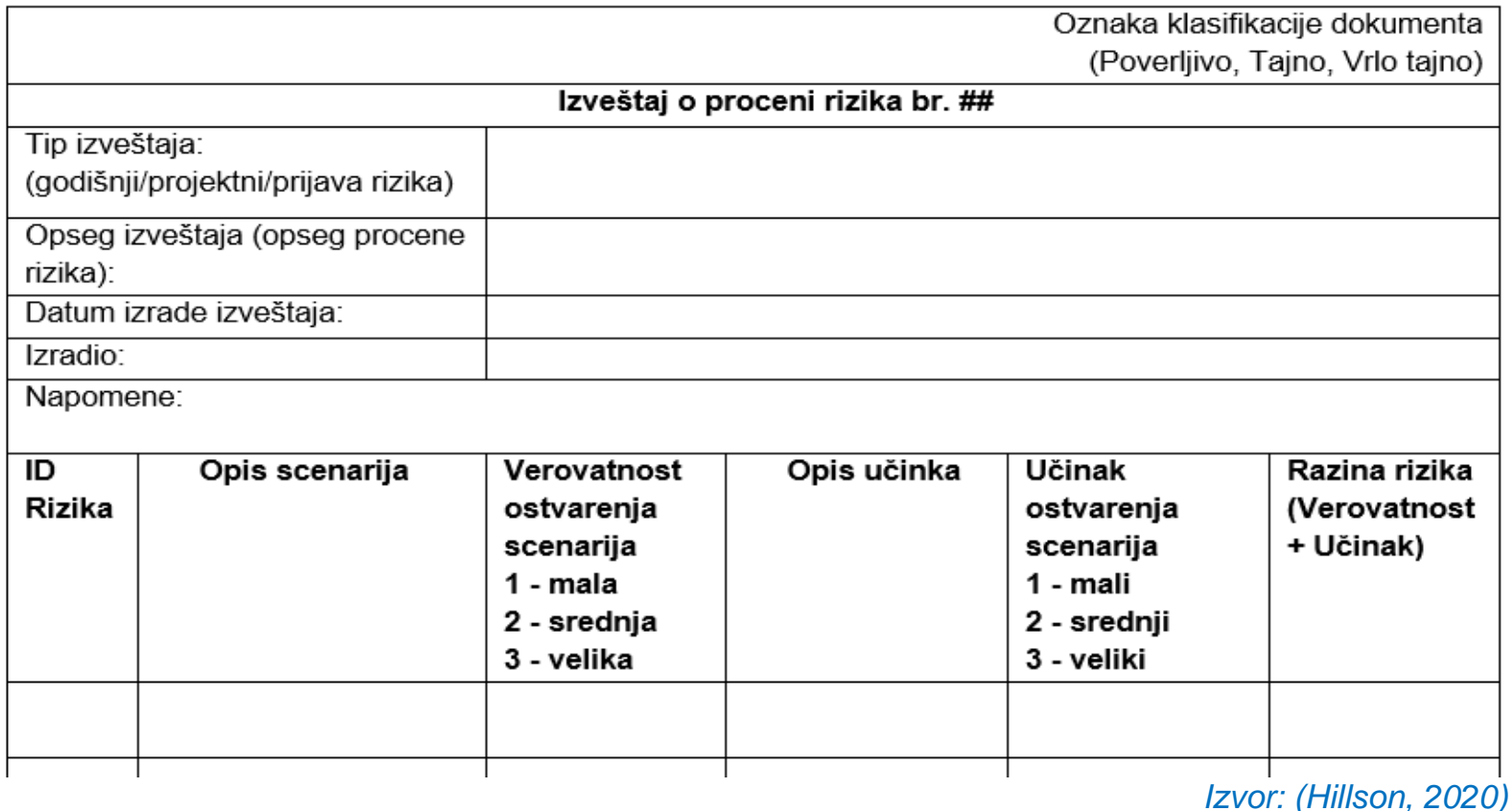

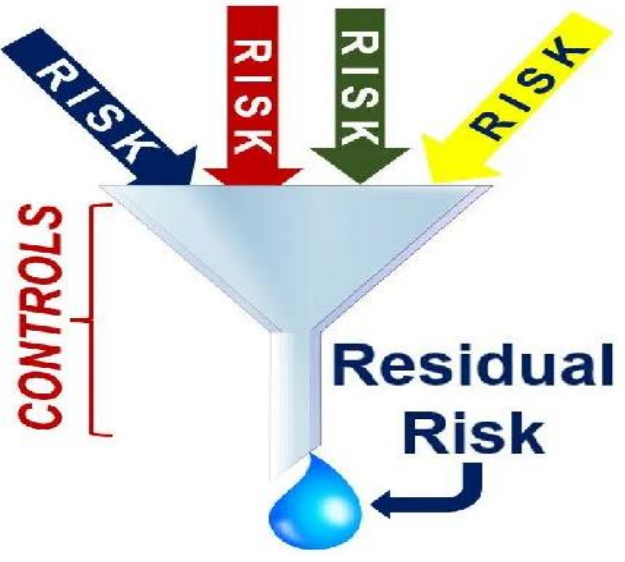

Slika 4 - Slikoviti prikaz inherentnog i rezidualnog rizika

\subsection{Inherentni i rezidualni rizik}

Inherentni rizik je identifikovani rizik pre primene mera tretiranja.

Rezidualni rizik je rizik kod kojeg se uzimaju u obzir postojeće mere tretiranja koje ublažavaju rizik.

Nivo rizika koji je ostao nakon primene mera tretiranja.

Inherentni rizik - mere tretiranja = rezidualni rizik

\subsection{Kriterijumi za prihvatanje rizika}

Odluka o prihvatljivom nivou rizika donosi se na osnovu izveštaja o proceni rizika i proceni kakve 
posledice po poslovni proces može uzrokovati ostvarenje rizika pojedinog nivoa. U skladu s trenutnim stanjem, svi rizici nivoa 4 i niži (ili neki drugi nivoi) smatraju se prihvatljivima, te na njih nije potrebno delovati. Rizici nivoa 5 i 6 su neprihvatljivi i potrebno in je umanjiti implementacijom sigurnosnih kontrola, izbegavanjem aktivnosti koje uzrokuju rizik ili prenošenjem rizika na treće strane.
Izjava o prihvatanju rizika je sastavni deo procesa upravljanja rizicima.

U izjavi organizacija zvanično iznosi svoj stav prema prihvatljivim i neprihvatljivim rizicima i deklariše svoj risk apetit i svoju risk toleranciju.

Organizacija obrazlaže koje rizike svesno prihvata, a koje tretira uz angažovanje odgovarajućeg resursa i primenu odgovarajućih tehnika i mera.

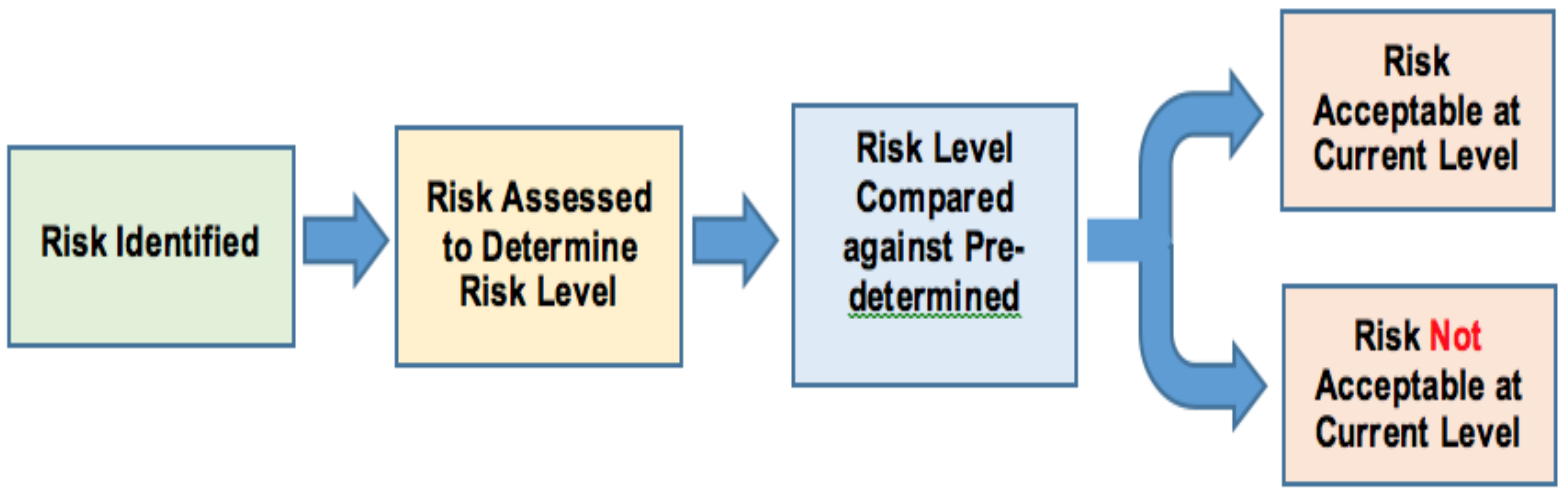

Slika 5 - Pregled procesa prihvatanja rizika

Izvor: (Paladin, 2017)

\subsection{Ublažavanje rizika putem kontrola}

U nastavku je prikazano deset mera kao odgovor na rizike čiji su uticaj i verovatnoća događanja već procenjeni:

- Okončati - ovaj odgovor je adekvatan ukoliko je rizik veliki i ne može se kontrolisati ili su troškovi takve kontrole veliki.

- Kontrole - jedno od osnovnih oružja za rešavanje rizika su bolje kontrole.

- Izmeniti - ukoliko se proceni da rizici imaju veliki uticaj, ali malu verovatnoću nastanka, možemo da poželimo da izmenimo strategiju raspodele rizika.

- Nepredviđene okolnosti - koristan odgovor na rizik koji ima veliki uticaj, a malu verovatnoću nastanka jer se zasniva na sačinjavanju planova za slučaj nepredviđenih okolnosti koje nastaju ukoliko se rizik materijalizuje.

- Pomeriti na viši nivo - kada ocena uticaja i verovatnoće pokažu da su uticaji i verovatnoća na minimalnom nivou za oba faktora, ovo ne znači obavezno da je sve u redu. Upravljanje rizikom podrazumeva znanje $u$ vezi sa tim gde treba utrošiti dragoceno vreme i gde treba utrošiti dragocene resurse. Oblasti u kojima su oba faktora na minimalnom nivou su pogodne za dalja ulaganja.

- Komunicirati - jedan aspekt upravljanja rizikom koji se često izostavlja u slučajevima kada postoji veliki uticaj i srednja ili velika verovatnoća, a kontrole ne mogu da umanje rizik na prihvatljiv nivo je strategija u okviru koje se postojanje ovakvog rizika saopštava akcionarima i obezbeđuje da oni budu svesni uticaja na sposobnost organizacije da bude sigurna u uspeh.

- Tolerisati - rizik koji ima mali uticaj i malu verovatnoću nasankane predstavlja pretnji i kao takav se može tolerisati.

- Naručiti istragu - većina razvijenih sistema za upravljanje rizikom obezbeđuje određeno vreme za razmatranje, pri čemu odluka može biti da se naruči istraga, odnosno da se ide dublje i otkrije više o riziku, njegovom uticaju i o verovatnoći nastanka.

- Obaveštenje - neki rizici sa velikim uticajem i velikom verovatnoćom se ne mogu interno razrešiti usled čega je neophodno obavestiti i angažovati strane koje se mogu smatrati eksternim stranama koje učestvuju u sprovođenju upravljanja rizikom. 
- Proveriti usaglašenost - poslednji u setu odgovora na rizik se ponekad lako predvidi. Reč je o usredsređivanju na oblasti u kojima su kontrole ključne za ublažavanje značajnih rizika, kao i o obezbeđivanju da kontrole zapravo funkcionišu kao što je i nameravano. (Pickett, 2005, str.58-60).

\subsection{Registri rizika}

Registri rizika deluju kao sredstvo za sumiranje svih procena i odluka donetih u vezi sa identifikovanim rizikom. Registar rizika služi za monitoring, vođenje evidencije o identifikovanim rizicima i za kontrolu primene mera tretiranja, pošto se plan tretiranja rizika nalazi u registru i predstavlja njegov sastavni deo. Registar takođe služi za arhiviranje rizika.

Registar treba da se ažurira kako bi se odrazile promene ciljeva, eksternih i internih rizika $i$ kontrola, koje nastaju kao rezultat promena okruženja u kome se posluje. Ulazni elementi registra i razvrstavanje značajnih rizika, nasuprot nematerijalnom riziku, zavisi od shvatanja rizika, to jest od sklonosti ka riziku odnosno tolerancije rizika.

Tabela 3. Prikaz primera forme registra rizika

\begin{tabular}{|c|c|c|c|c|c|c|c|c|c|c|c|c|c|c|c|}
\hline$\varrho$ & 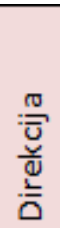 & 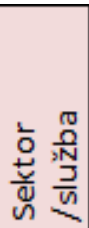 & $\underline{\simeq}$ & 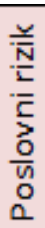 & 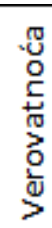 & 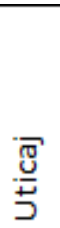 & $\begin{array}{l}\frac{\pi}{\bar{N}} \\
\frac{2}{2} \\
\frac{0}{2} \\
\frac{0}{2}\end{array}$ & 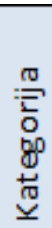 & 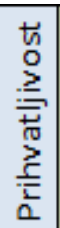 & 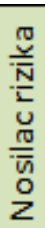 & 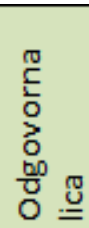 & 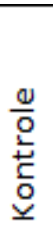 & 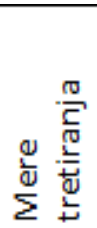 & 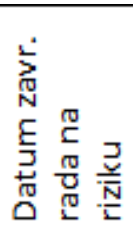 & 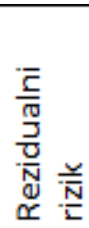 \\
\hline 1 & & & $\mathrm{DA}$ & & & & & & & & & & & & \\
\hline & & & & & & & & & & & & & & & \\
\hline & & & & & $\mathrm{V}^{*}$ & & $\mathrm{~N}$ & & & & & & & & \\
\hline & & & & & & & & & & & & & & & \\
\hline & & & & & & & & & & & & \multicolumn{3}{|c|}{ Plan tretiranja } & \\
\hline
\end{tabular}

Odbor ima odgovornost da obezbedi da se rizicima upravlja. U praksi će odbor delegirati upravljanje okvirom za upravljanje rizikom rukovodećem timu - koji će biti odgovoran za izvršavanje određenih aktivnosti. Mogu postojati i odvojene funkcije koje koordiniraju i rukovode ovim aktivnostima - koje poseduju specijalističke veštine i znanja.

Svi u organizaciji igraju ulogu u obezbeđivanju upravljanja rizicima preduzeća, ali je primarna odgovornost za identifikovanje tih rizika na rukovodstvu.

\subsection{Koristi od upravljanja rizicima preduzeća}

Upravljanje rizicima preduzeća može dati veliki doprinos, u pružanju pomoći organizaciji da na putu dostizanja svojih ciljeva upravlja rizicima.

Koristi uključuju:

- Veću verovatnoću dostizanja tih ciljeva

- Konsolidovano izveštavanje o različitim rizicima na nivou odbora

- Poboljšano razumevanje ključnih rizika i njihove šire implikacije
- Identifikuju i podelu unakrsnih poslovnih rizika

- Veće fokusiranje rukovodstva na pitanja koja su od stvarnog značaja

- Manje iznenađenja i kriza

- Veće interno fokusiranje na to da se urade prave stvari na pravi način

- Sposobnost da se preuzme veći rizik za veću nagradu

- Preuzimanje rizika i donošenje odluka na osnovu većeg stepena informisanosti (UIRS, 2015, str. 217)

\section{ULOGA INTERNE REVIZIJE U UPRAVLJANJU RIZIKOM}

U skladu a Međunarodnim standardom implementacije interne revizije 1220 A3 Instituta Internih revizora (IIA) se navodi da interni revizori moraju da imaju u vidu ključne rizike i da interni revizor treba da obrati pažnju na značajne rizike koji mogu da utiču na ciljeve, poslovanje i resurse. U Međunarodnom standardu izvođenja 2100 se tvrdi da aktivnost interne revizije treba da proceni i doprinese unapređenju procesa upravljanja rizikom, kontrole i upravljanja korišćenjem 
sistematskog i disciplinovanog pristupa dok se u standardu 2110 A navodi da aktivnost interne revizije treba da prati i procenjuje efektivnost sistema upravljanja rizikom organizacije.

Aktivnost interne revizije mora da ocenjuje efektivnost $\mathrm{i}$ da doprinosi unapređenju procesa upravljanja rizikom. Ona mora oceniti izloženost riziku u vezi korporativnog upravljanja, poslovanja i informacionih sistema organizacije u odnosu na:

- Pouzdanost i integritet finansijskih i poslovnih informacija

- Efektivnost i efikasnost poslovnih procesa

- Zaštitu imovine

- Usklađenost sa zakonima, drugim propisima i ugovorima

Odrediti da li je proces upravljanja rizikom efektivan, podrazumeva prosuđivanje proisteklo iz ocene internog revizora:

- Da su ciljevi organizacije usklađeni i podržavaju misiju organizacije

- Da su identifikovani i ocenjeni značajni rizici

- Da su odabrana adekvatna rešenja za kontrolu rizika a u skladu sa sklonošću organizacije da ima takvu vrstu rizika

- Da su relevantne informacije o riziku zabeležene i pravovremeno saopštene organizaciji, omogućavajući zaposlenima, rukovodstvu i odboru da izvršavaju svoje obaveze

- Interna revizija se može naći u jednoj od sledeće četiri etape:

- Da nema ulogu

- Revizija procesa upravljanja rizikom

- Aktivna kontinuirana podrška upravljanja rizikom

- Upravljanje i koordinacija procesa upravljanja rizikom

Na ovaj način se određuje uloga interne revizije u procesu upravljanja rizikom $u$ nadležnosti izvršnog rukovodstva i komiteta za reviziju. Interni revizori mogu da imaju veoma aktivnu ulogu u procesu upravljanja rizikom, ali ne treba da budu nosioci ili direktno odgovorni za proces upravljanja identifikovanim rizicima. Praktični savet (2110-1) definiše kako interna revizija treba da adekvatnost procesa upravljanja rizikom.

Uloga interne revizije u procesu upravljanja rizikom se identifikuje kroz model od sledećih sedam pristupa:
1. Usvojen je standardni pristup revizijskog pregleda. Tim interne revizije prati način na koji je uspostavljeno i implementirano sistemsko upravljanje rizikom a zatim se pregleda da li je proces pouzdan, čvrst i da li zadovoljava potrebe organizacije.

2. Interna revizija može da vrši relevantne prezentacije odboru i da učestvuju na sastancima ili radionicama na kojima se razmatra i usmerava proces upravljanja rizikom.

3. Interni revizori se uključuju u promovisanje potrebe za procesom upravljanja rizikom, organizuju različite seminare i događaje kojima se promoviše korporativno upravljanje, upravljanje rizikom i kontrola.

4. Interna revizija organizuje kontrolnu samoprocenu i prenosi poruku o upravljanju rizikom kroz sve nivoe organizacije.

5. Interna revizija sačinjava bazu o korporativnom riziku na osnovu svih aktivnosti koje se zasnivaju na riziku.

6. Uspostavljanje dva odvojena odeljenja službe interne revizije. Prvi se fokusira na usluge uveravanja i pregleda, drugi deo vrši usluge konsaltinga vezi sa organizovanjem kontrolne samo procene rizika.

7. Finaliziranje rada na uspostavljanju sistematskog upravljanja rizikom u organizaciji i početak funkcionisanje procesa. Nakon što pruži pomoć u uspostavljanju procesa, interna revizija prestaje sa aktivnostima konsaltinga i vraća se osnovnoj ulozi pružanja uveravanja. (Pickett, 2005, str. 77-80)

Aktivnosti uveravanja - one čine deo širih ciljeva pri davanju uveravanja o upravljanju rizicima. Interna revizija koja je usaglašena sa Međunarodnim standardima za profesionalnu praksu interne revizije može i treba da obavlja neke od navedenih aktivnosti.

Interna revizija može da obezbedi konsalting usluge kojima se unapređuje korporativno upravljanje u organizaciji, upravljanje rizikom i kontrolni procesi. Stepen konsaltinga koji pruža interna revizija u upravljanju rizicima preduzeća zavisiće od drugih resursa, internih i eksternih, koji stoje na raspolaganju odboru, kao i zrelosti organizacije u pogledu rizika i verovatno će varirati s vremenom. 
Aktivnosti koje interna revizija ne treba da preduzima - ona može da proširi svoje uključivanje u proces upravljanja rizicima preduzeća s tim da se obezbedi primena određenih uslova:

- Treba da bude jasno da menadžment ostaje odgovoran za upravljanje rizikom

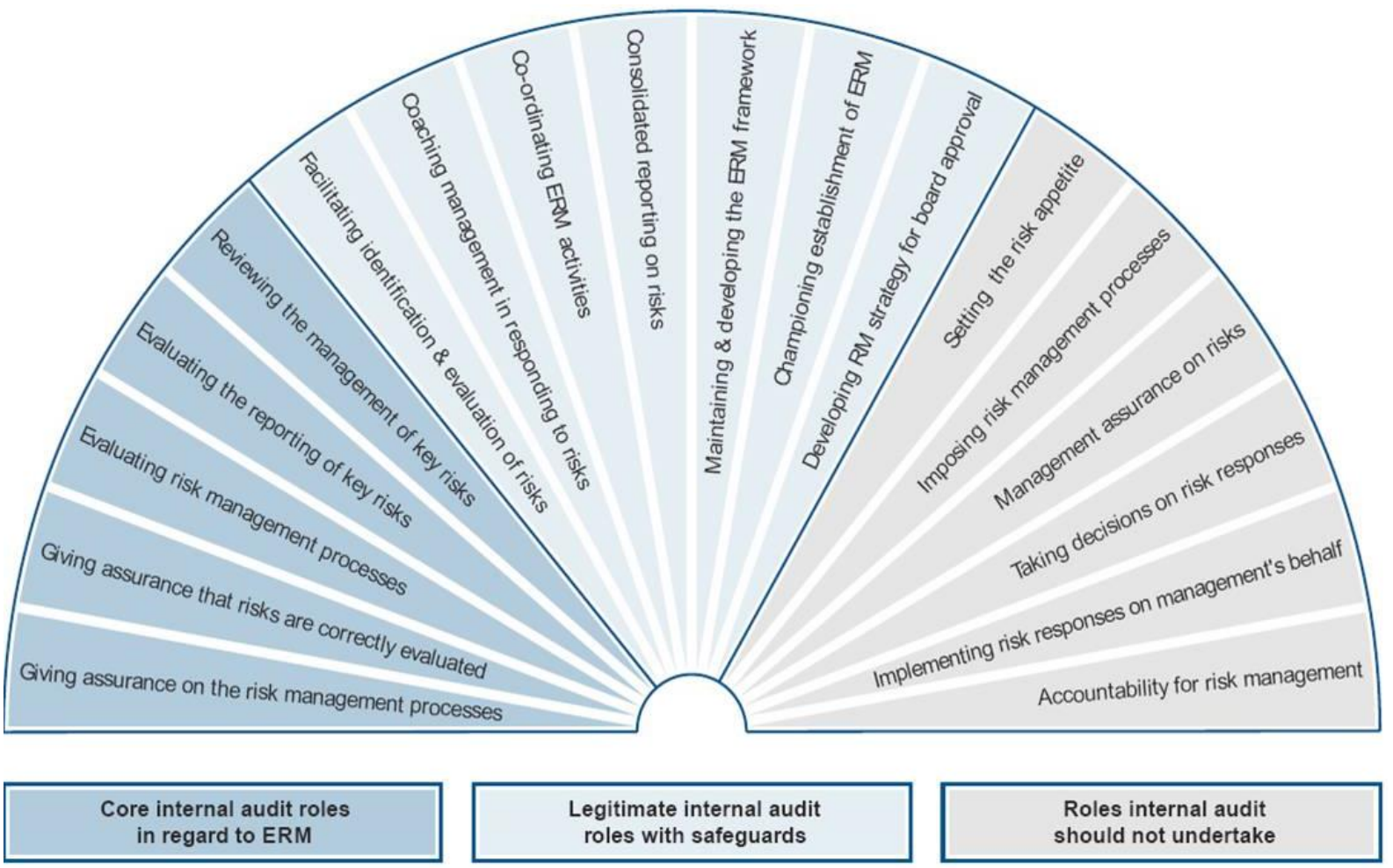

Slika 6 - Slikovni prikaz aktivnosti interne revizije u procesu upravljanja rizicima

Izvor: (Wheeler, 2009)

- Priroda odgovornosti internih revizora treba da bude dokumentovana u povelji interne revizije i odobrena od strane odbora za reviziju

- Ni jednim rizikom, za račun menadžmenta, ne treba da upravlja interna revizija

- Interna revizija treba da obezbedi savet, izazov i podršku procesu donošenja upravljačkih odluka, sto je suprotno preuzimanju samih odluka

- Interna revizija ne može istovremeno da pruža objektivno uveravanje za ma koji deo okvira za upravljanje rizicima preduzeća za koji je ona odgovorna (UIRS, 2015, str. 219220).

\section{ZAKLJUČAK}

Procesom upravljanja rizikom se kreira platforma za korporativno upravljanje uz pružanje uveravanja akcionarima i drugim stejkholderima da njihovi izabrani predstavnici razumeju rizik koji se odnosi na njihove investicije i da ih menadžment sustinski razmatra. Upravljanje rizikom se pre svega odnosi na promenu kulture organizacije tako da zaposleni prihvataju svoje odgovornosti, uz razumevanje da je to instrument koji će im pomoći u prevazilaženju problema i omogućiti sistematičnije poslovanje. Interni revizori se suočavaju sa veoma velikim izazovom prilikom definisanja svoje uloge u razvoju procesa upravljanja rizikom. (Pickett, 2005, str. 81). Rast, konzistentni prinosi i kapital su ugroženi ako se rizik ne kontroliše. Uspeh upravljanja rizikom na nivou celog preduzeća zavisi od integrisanog procesa procene rizika $\mathrm{i}$ ispravnog načina upravljanja rizicima u celoj organizaciji. Ukoliko članovi odbora ne podržavaju proces upravljanja rizikom, gotovo je sigurno da će proces biti neuspešan. Odbor je odgovoran za celokupni proces upravljanja rizikom kao i za formiranje mišljenja o efektivnosti procesa. Jedan od ključnih zahteva odbora ili njegovog ekvivalenta jeste da dobije uveravanje da je proces upravljanja rizicima efektivan i da su ključni rizici upravljanje svedeni na prihvatljiv nivo. 


\section{CITIRANA DELA}

Herrera, M. (2013, 05 17). Four Types of Risk Mitigation and BCM Governance, Risk and Compliance. Preuzeto sa MHA Consulting: https://www.mha-it.com/2013/05/17/four-types-of-risk-mitigation/

Hillson, D. (2020, 07 26). Residual Risk. Preuzeto sa YouTube: https://www.youtube.com/watch?app=desktop\&v=ZZPYD8rTIKE

Paladin. (2017, 04 19). Risk Tip \#5 - Hungry to understand risk appetite? Preuzeto sa Paladin Risk Management Services: https://paladinrisk.com.au/risk-tip-5-hungry-understand-risk-appetite/

Pickett, K. S. (2004). Interni revizor u praksi. Beograd: Savez računovođa i revizora Srbije.

Pickett, K. S. (2005). Osnovni priručnik za internu reviziju. Beograd: Savez računovođa i revizora Srbije.

PRINCE2 Revision. (n.d.). Risk (RK) - Managing threats and opportunities. Retrieved from sites.google.com: https://sites.google.com/site/mhprince2revision/themes/risk-rk

UIRS. (2015). Zbirka smernice interne revizije: MOPP, stanovišta, modeli. Beograd: Udruženje internih revizora Srbije.

Wheeler, J. A. (2009, 03 25). Internal Audit is a Key ERM Component. Preuzeto sa wheelhouseadvisors: http://wheelhouseadvisors.blogspot.com/2009/03/in-recent-webinar-toinstitute-of.html

Received for publication: $\quad 10.11 .2020$.

Revision received: $\quad 15.02 .2021$.

Accepted for publication: $\quad$ 05.04.2021.

Kako citirati ovaj rad? / How to cite this article?

Style - APA Sixth Edition:

Jović, Z. (2021, 04 15). Upravljanje rizicima i interna revizija. (Z. Čekerevac, Ur.) FBIM Transactions, 9(1), 48-57. doi:10.12709/fbim.09.09.01.05

Style - Chicago Sixteenth Edition:

Jović, Zorica. 2021. „Upravljanje rizicima i interna revizija.“ Urednik Zoran Čekerevac. FBIM Transactions (MESTE) 9 (1): 48-57. doi:10.12709/fbim.09.09.01.05.

Style - GOST Name Sort:

Jović Zorica Upravljanje rizicima i interna revizija [Časopis] // FBIM Transactions / ur. Čekerevac Zoran. - Beograd : MESTE, 1504 2021. - 1 : T. 9. - str. 48-57.

Style - Harvard Anglia:

Jović, Z., 2021. Upravljanje rizicima i interna revizija. FBIM Transactions, 15 04, 9(1), pp. 48-57.

Style - ISO 690 Numerical Reference:

Upravljanje rizicima i interna revizija. Jović, Zorica. [ur.] Zoran Čekerevac. 1, Beograd : MESTE, 1504 2021, FBIM Transactions, T. 9, str. 48-57. 